\title{
Rantai Pasok Industri Baja untuk Pembangunan PLTN di Indonesia
}

\author{
Dharu Dewi*, Sahala M. Lumbanraja \\ ${ }^{1}$ Pusat Kajian Sistem Energi Nuklir,BATAN, Jl. Kuningan Barat, Jakarta Selatan
}

\begin{tabular}{l}
\hline INFORMASI ARTIKEL \\
\hline Riwayat Artikel: \\
Diterima: \\
7 Juni 2017 \\
Diterima dalam bentuk revisi: \\
21 Juni 2017 \\
Disetujui: \\
21 Juni 2017 \\
\end{tabular}

Kata kunci:

Rantai pasok Industri baja konstruksi

PLTN

\begin{abstract}
ABSTRAK
RANTAI PASOK INDUSTRI BAJA UNTUK PEMBANGUNAN PLTN DI INDONESIA. Dalam pembangunan Pembangkit Listrik Tenaga Nuklir (PLTN) dibutuhkan material baja untuk pembuatan komponen berat maupun material struktur untuk konstruksi sipilnya. Industri nasional diharapkan mampu memasok komponen baja PLTN khususnya untuk kebutuhan komponen non nuklir. Rantai pasok industri baja sangat diperlukan untuk mengetahui potensi industri baja dari hulu sampai hilir yang diharapkan dapat mendukung pembangunan PLTN tersebut secara berkelanjutan. Jenis baja yang dibutuhkan dalam konstruksi PLTN adalah baja struktur, rebar, pelat baja dan lain-lain. Tujuan penelitian ini adalah mengidentifikasi rantai pasok industri baja dari industri hulu sampai hilir sehingga dapat melihat kemampuan industri nasional dalam memasok kebutuhan baja untuk pembangunan PLTN. Metodologi yang digunakan adalah kajian literatur dan survei industri dengan cara purposive sampling test yakni mengirimkan kuesioner dan melakukan kunjungan teknis ke industri yang dianggap berpotensi memasok komponen baja untuk konstruksi PLTN. Dari hasil analisis terhadap kuesioner dan survei telah diperoleh industri baja Indonesia yang mampu memasok baja untuk bahan konstruksi PLTN non nuklir, yaitu PT. Krakatau Steel, PT. Gunung Steel Group (PT. Gunung Garuda dan PT. Gunung Raja Paksi), PT. Cilegon Fabricators dan PT. Ometraco Arya Samanta. Sedangkan bahan baja untuk komponen utama dengan grade nuklir, seperti bahan baja untuk bejana reaktor dan bejana tekan, industri baja Indonesia belum mampu memasoknya, karena belum memenuhi persyaratan spesifikasi, kode dan standar grade nuklir Oleh karena itu, industri baja Indonesia harus meningkatkan kemampuan, baik dalam pengolahan bahan baku dan kemampuan fabrikasi agar dapat memenuhi persyaratan tersebut.
\end{abstract}

\begin{abstract}
SUPPLY CHAIN OF STEEL INDUSTRIES FOR THE NUCLEAR POWER PLANT CONSTRUCTION IN INDONESIA. Nuclear Power Plant (NPP) Construction needs steel materials for the manufacturing of heavy components and civil work construction. National industries is expected to supply steel components especially for non nuclear component needs. Supply chain of steel industries is required to know the potency of steel industries from upstream to downstream industries which can support the NPP construction sustainability. The type of steel needed in the NPP construction consist of structure steel, rebar, steel plate, etc. The aim of the study is to identify supply chain of steel industries from upstream industries to downstream industries so that they can supply steel needs in the NPP construction. The methodology used are literature review and industries survey by purposive sampling test which sent questionnaires and carrying out technical visits to the potential industries to supply steel components for NPP construction. From the analysis of the questionnaires and survey, it has been obtained that the Indonesian steel industries capable of supplying steel for construction materials of non-nuclear parts are PT. Krakatau Steel, PT. Gunung Steel Group (PT Gunung Garuda and PT. Gunung Raja Paksi), PT. Cilegon Fabricators and PT. Ometraco Arya Samanta.While steel materials for primary components with nuclear grade, such as steel materials for reactor vessels and pressure vessels, the Indonesian steel industry has not been able to supply them. Therefore, the Indonesian steel industries must improve its capability, both in raw material processing and fabrication capability in order to meet the requirements of specifications, codes and standards of nuclear grade.
\end{abstract}

Keywords: supply chain, steel industries, construction, nuclear power

\section{PENDAHULUAN}

BATAN sebagai lembaga penelitian dan pengembangan telah melakukan studi pengembangan energi nuklir untuk diimplementasikan di masa mendatang. Perencanaan implementasi pembangunan
PLTN harus dilakukan sejak awal sehingga nantinya pembangunan PLTN dapat dilaksanakan sesuai dengan jadwal yang ditentukan. Untuk memenuhi kebutuhan energi secara berkelanjutan, maka salah satu opsi yang dapat dilakukan adalah dengan menggunakan PLTN. Pembangunan PLTN 
memerlukan rantai pasok industri yang dapat memasok material dan komponen yang dibutuhkan secara berkelanjutan.

Rantai pasok industri yang berkelanjutan untuk pembangunan PLTN perlu dipertimbangkan secara matang sehingga tidak terjadi penundaan jadwal pengiriman material maupun komponen ke tapak PLTN. Penundaan aliran pengiriman material diidentifikasi sebagai salah satu sumber risiko rantai pasok yang menunjukkan buruknya mutu rantai pasok dan kurangnya kemampuan pemasok untuk memenuhi permintaan [1]. Secara garis besar,sumber risiko utama rantai pasok meliputi penundaan, gangguan aliran material (masalah transportasi), ketidakakuratan prediksi/proyeksi perusahaan dalam pemenuhan permintaan, kegagalan pengadaan akibat fluktuasi pertukaran uang (exchange rate), masalah cadangan dan kapasitas [2].

Dalam pembangunan PLTN dibutuhkan rantai pasok dari industri hulu (material bahan baku) sampai menjadi industri hilir (material jadi) untuk pekerjaan konstruksi sipil maupun manufaktur komponen berat PLTN. Permasalahan yang ada terkait rantai pasok adalah rantai pasok sangat bergantung pada penyediaan bahan baku agar dapat mempertahankan produksi secara berkelanjutan dan proses kontruksi PLTN tidak mengalami penundaan waktu. Koordinasi dan integrasi rantai pasok industri dari hulu sampai hilir sangat diperlukan untuk keberlanjutan pasokan material dalam pembangunan PLTN.

Makalah ini difokuskan pada kajian mengenai rantai pasok industri baja untuk dapat mendukung Pembangunan PLTN di Indonesia[3]. Beberapa kajian sebelumnya yang terkait rantai pasok yakni mengenai Rantai Pasok Industri Konstruksi Sipil untuk mendukung program PLTN di Indonesia [4,5] dan juga Rantai Pasok Industri Semen untuk Mendukung Progam Kostruksi PLTN di Indonesia (Supply Chain of Cement Industry to Support the NPP Construction Program in Indonesia[6]. Makalah rantai pasok tersebut saling berhubungan dan saling terkait satu sama lain, karena dalam proyek pembangunan PLTNdibutuhkan hubungan antara rantai pasok industri jasa konstruksi sipil, industri baja, industri semen maupun industri pendukung lainnya.

Tujuan penelitian ini adalah mengidentifikasi rantai pasok industri baja dari industri hulu sampai hilir sehingga dapat melihat kemampuan industri nasional dalam memasok kebutuhan baja untuk pembangunan PLTN. Kedepannya industri baja Indonesia diharapkan dapat memasok dan berpartisipasi aktif dalam pembangunan PLTN di Indonesia. Manfaat studi ini dapat digunakan oleh pemangku kepentingan sebagai bahan masukan industri baja yang berpotensi dan bagi para pelaku industri untuk meningkatkan dan mengembangkan kemampuan spesifikasi, kode dan standar sesuai dengan grade nuklir PLTN.

\section{TEORI}

Manajemen rantai pasok dapat mengurangi biaya manufaktur dengan cara mengoptimimalkan rantai pasok mulai dari bahan baku hingga pengguna akhir (end users) [7].

Peta rantai pasok dibutuhkan untuk memberikan gambaran tentang rantai alir material dan dampak lingkungan yang ditimbulkannya. Hal ini kemudian membentuk basis unjuk kerja lingkungan dari rantai pasok produk dan mengidentifikasi cara untuk mengelola dampaknya [8, 9].

Pengkajian unjuk kerja rantai pasok telah menjadi daya tarik yang besar dalam beberapa literatur dan merupakan cara sistimatik pengukuran unjuk kerja berkelanjutan dari kegiatan rantai pasok[10]. Pengukuran unjuk kerja rantai pasok secara berkelanjutan baik langsung maupun tidak langsung menggunakan metode yang cocok sangat bermanfaat untuk mengidentifikasi area peningkatan unjuk kerja [11].

Sektor Industri nuklir memainkan peranan penting dalam kegiatannya untuk mengidentifikasi tantangan dan melakukan tindakan untuk menghadapinya [12]. Salah satu contoh tantangan dalam rantai pasok industri adalah keterlambatan pengiriman yang disebabkan oleh perencanaan yang buruk. Kesalahan fabrikasi bejana tekan untuk PLTN Flamanville di Perancis dan dua reaktor Taishan di China oleh vendor AREVA 
merupakah kegagalan yang paling serius [13]. Dalam rantai pasok, pemasok harus memastikan persyaratan kontrak, persyaratan manual mutu, persyaratan standar yang sesuai, dan persyaratan penting lainnya untuk pengiriman produk dan jasa sesuai spesifikasi[14]. Manajemen rantai pasok dipertimbangkan sehingga keberhasilan dan keuntungan dapat tercapai dan terpenuhinya sasaran organisasi yang lebih besar antara lain pelayanan pelanggan yang lebih baik dan daya saing yang meningkat[15].

Pemetaan rantai pasok industri baja sangat diperlukan untuk mendukung pembangunan PLTN. Industri baja merupakan salah satu industri yang berkontribusi besar untuk mendukung pembangunan PLTN di Indonesia. Baja sebagai salah satu komponen yang terkait dengan pekerjaan konstruksi sangat diperhitungkan kekuatannya terhadap aspek ketahanan terhadap gempa. Kejadian seismik yang melebihi basis desain gempa (design basis earthquakes (DBE) dapat terjadi di PLTN $[16,17,18]$.

\section{METODOLOGI}

Metodologi yang digunakan pada penelitian ini adalah:

- Melakukan kajian literatur terkait industri baja nasional (profil industri, website/internet, dan data dari Kementerian Perindustrian).

- Membuat dan mengirimkan kuesioner ke industri baja. Isi kuesioner mencakup nama industri, kemampuan industri, pengalaman keterlibatan dalam pembangunan pembangkit listrik, daftar Sistem Manajemen Mutu, rantai pasokan industri, dan daftar nama perusahaan partner dalam penyediaan bahan baku/barang setengah jadi/barang jadi dan nama negara/daerah pemasok bahan baku. Pengiriman kuesioner dilakukan ke industri baja dengan metode purpossive sampling test yakni mengambil sampel data industri baja yang dianggap memiliki potensi untuk berpartisipasi dalam pembangunan PLTN di Indonesia. Pengiriman kuesioner ke industri baja tersebut adalah sebagai berikut: 1) PT. Krakatau Steel, 2) PT. Gunung Steel Group 3) PT. Cilegon Fabricators 4) PT. Ometraco
Arya Samantha 5) PT. Amarta Karya. 6) PT. Arkon Prima Indonesia 7) PT. Gunawan Dian Jaya Steel 8) PT. Master Steel dan 9) PT. Cakra Steel

- Melakukan survei/kunjungan teknis industri baja yang dianggap berpotensi dalam pembangunan PLTN yakni ke PT. Krakatau Steel, PT. Gunung Steel Group, PT. Cilegon Fabricators, dan PT. Ometraco Arya Samanta.

- Melakukan analisis data hasil kuesioner dan survei industri.

\section{HASIL DAN PEMBAHASAN}

Material baja yang merupakan bahan baku pembuatan komponen PLTN dan beton sangat diperlukan dalam konstruksi PLTN. Dalam rangka untuk mendukung keselamatan, fasilitas nuklir menggunakan dinding ruang untuk Generator Uap, presssurizer dan lainlain. Dinding ruang yang digunakan berbentuk beton bertulang dengan ketebalan sekitar 24 60 inci yang berfungsi sebagai penghalang radiasi dan diharapkan sebagai sistem penahan gaya lateral jika terjadi gempa[19]. Dinding beton bertulang didesain memenuhi kode ACI 349. Beton bertulang terdiri dari komposit pelat baja, grid rebar dan tie bar. Misalnya pada AP1000, pelat baja berfungsi untuk meningkatkan daya dukung pengungkung agar mampu menahan dampak jatuhnya pesawat[20].

Baja Feritik telah dipertimbangkan sebagai calon material struktur untuk pembangkit listrik sejak tahun 1970-an. Baja feritik lebih tahan penggelembungan (swelling) daripada baja stainless austenitik[21]. Sebagai gambaran, pada konstruksi satu unit PLTN 1000 MWe membutuhkan material sekitar $300.000 \mathrm{~m}^{3}$ beton dan puluhan ribu ton baja, dimana pada bagian struktur tertentu mensyaratkan spesifikasi khusus (special grade). Beberapa komponen manufaktur harus sudah mulai difabrikasi dalam waktu dua atau tiga tahun sebelum penuangan pertama beton struktur untuk konstruksi [22].

Sebagai gambaran kebutuhan baja untuk PLTN Generasi III+ (GEN III+) dengan kapasitas daya 1000 MWe di Amerika Serikat adalah sebagai berikut [23, 24]: 
a. Baja tulangan (Reinforced Steel) dan bagian-bagiannya sekitar 46.000 ton

b. Structural Steel, Miscellaneous Steel dan Decking sekitar 25.000 ton

Jumlah material yang dibutuhkan sangat tergantung pada lokasi dan kondisi tapak, seperti kedalaman bedrock[23].

Kemampuan industri baja sangat bergantung pada penyediaan bahan baku agar dapat mempertahankan produksi secara berkelanjutan. Rantai pasok industri baja sangat diperlukan dalam pembangunan PLTN karena merupakan jaringan dengan industri konstruksi sipil, industri semen dan industri penyedia bahan baku yang harus saling terintegrasi. Gambar 1 menunjukkan penggunaan baja dan struktur baja dalam pembangunan suatu PLTN.

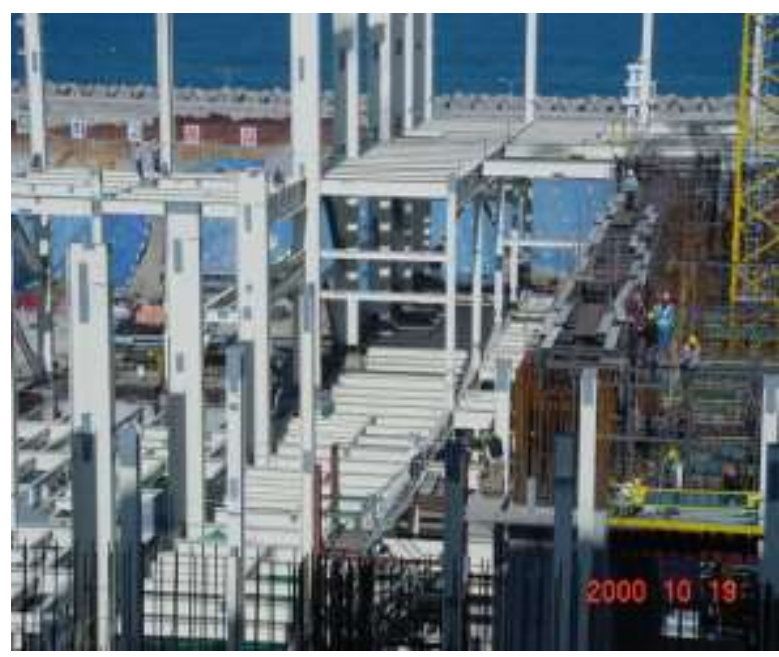

Gambar 1. Penggunaan baja dan struktur baja dalam pembangunan PLTN di Korea Selatan [25]

Pengiriman kuesioner ke industri baja dilakukan pada tahun 2012 dan data ini masih valid karena rantai pasok baja umumnya memiliki kontrak jangka panjang. Berdasarkan hasil kuesioner yang telah dikirimkan kembali oleh pihak industri baja ke BATAN, dari 9 kuesioner yang dikirimkan ke industri baja, hanya ada 4 industri baja yang telah merespon kuesioner tersebut yaitu PT. Krakatau Steel, PT. Gunung Steel Group (Group PT. Gunung Garuda \& PT. Gunung Raja Paksi), PT. Cilegon Fabricators dan PT. Ometraco Arya Samanta. Selain pengiriman kuesioner juga dilakukan kunjungan teknis ke 4 industri tersebut untuk mengetahui lebih mendalam data dan informasi tentang rantai pasok masing-masing industri.
Gambaran rantai pasok industri dari PT. Krakatau Steel, PT. Gunung Steel Group, PT. Cilegon Fabricators dan PT. Ometraco Arya Samanta dapat dilihat pada Gambar 2, Gambar 3, dan Gambar 4.

Hasil kuesioner yang diperoleh, ditunjukkan pada Gambar 2, Gambar 3, dan Gambar 4. Data yang telah diperoleh menunjukkan bahwa produk yang dihasilkan oleh PT. Krakatau Steel adalah hot rolled coil/plate/sheet dengan kapasitas 2.400.000 ton per tahun, cold rolled coil/sheet dengan kapasitas 850.000 ton per tahun dan wire rod dengan kapasitas 600.000 per tahun. PT. Krakatau Steel juga memproduksi bahan baku sponge iron, steel slab dan steel billet untuk keperluan produksi baja. Rantai pasok bahan baku baja selain hasil produksi dalam negeri, juga diimpor dari beberapa negara antara lain Brazil, Bahrain, Peru, Amerika, Cina, India, Hongkong. Slab impor berasal dari Korsel, Brazil danJepang. Billet impor berasal dari Korea Selatan dan Jepang. Sedangkan scrap impor berasal dari Korea Selatan, USA, Cina, dan dari industri lokal. Dari data di atas, bahan baku baja sebagian besar diperoleh dari impor. Pengalaman PT. Krakatau Steel dalam memasok pembangkit listrik konvensional antara lain membangun anak perusahaan yang bergerak dalam bidang pelayanan jasa listrik yakni PT. Krakatau Daya Listrik (PT. KDL).

PT. Gunung Steel Group yang merupakan kelompok PT. Gunung Garuda dengan PT. Gunung Raja Paksi, bahan baku baja berupa slab dan scrap berasal dari Brazil, Ukraina, dan industri lokal. Hasil produk yang dihasilkan oleh grup tersebut antara lain material H-Beam 1.000.000 MT, Angle 60.000 MT, IWF 1.000.000 MT, Steel Plate 900.000 MT, Hot Roll Coil 900.000 MT dan lain-lain. PT. Gunung Steel Group mempunyai pengalaman dalam memasok proyek PT, Krakatau Engineering dan PT. Krakatau Posco.

PT. Cilegon Fabricators memproduksi struktur baja (jasa) sebesar 12.000 ton per tahun, Boiler Pressure Part 5000 ton per tahun, pemipaan 2000 ton per tahun, modul Heat Recovery Steam Generator (HRSG) 6000 ton per tahun, Casing dan Ducting 1500 ton per tahun.

Bahan baku untuk struktur baja, casing dan ducting berasal dari Korea, Jepang, dan 
Indonesia yakni berasal dari daerah Surabaya dan Cikarang. Untuk material pemipaan, modul HRSG dan Boiler Pressure Part berasal dari Korea, Jepang, Jerman, Perancis, Swedia dan Spanyol.

Pengalaman PT. Cilegon Fabricators dalam memasok pembangkit listrik konvensional adalah memasok baja untuk pembangunan PLTU Suralaya, PLTU Bukit Asam, PLTU Tanjung Jati, PLTU Paiton, PLTU Gresik, PLTGU Grati, PLTGU Cilegon, PLTGU Tanjung Priok, PLTGU Muara Karang dan lain - lain.

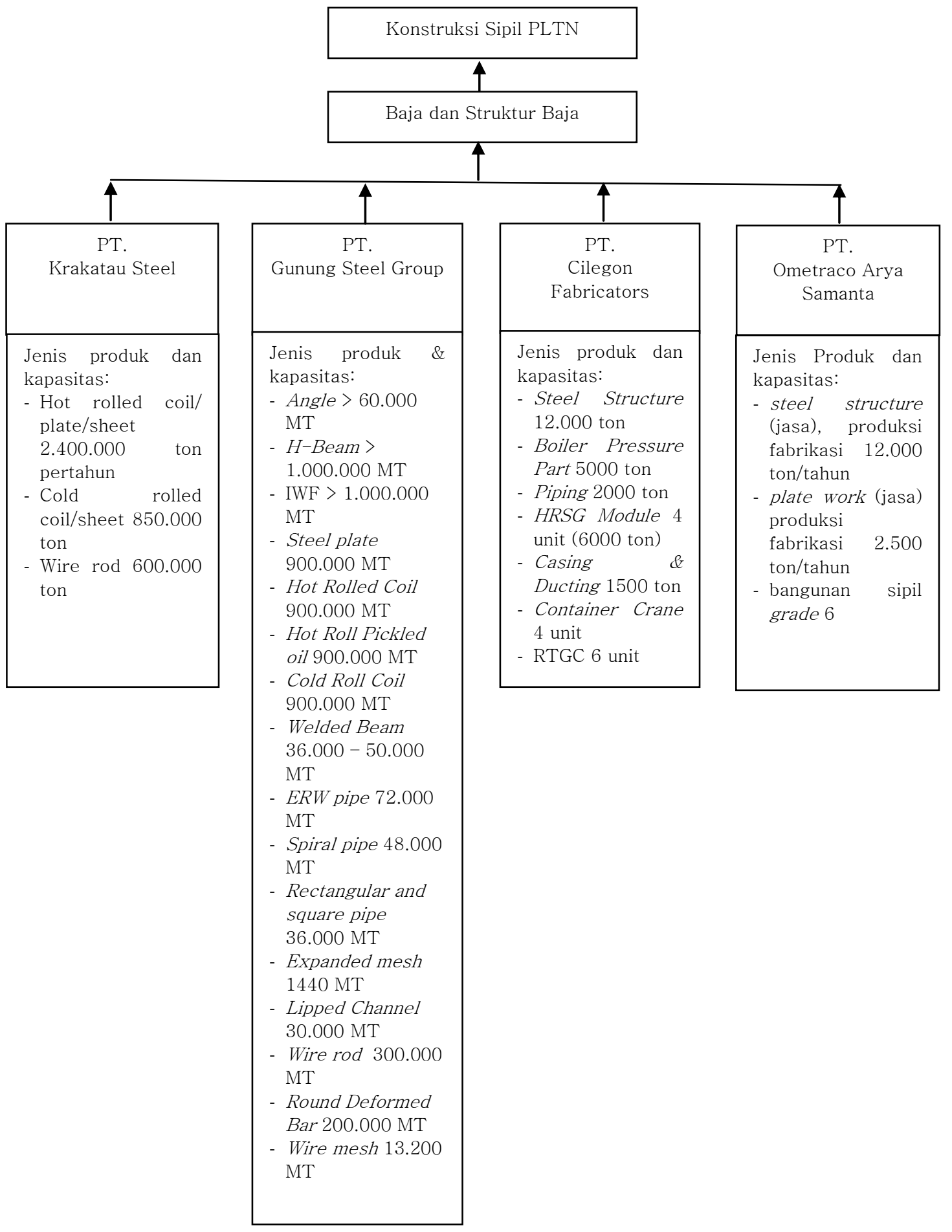

Gambar 2. Rantai Pasok Industri Baja berdasarkan Jenis Produk dan Kapasitas produk [26-29] 


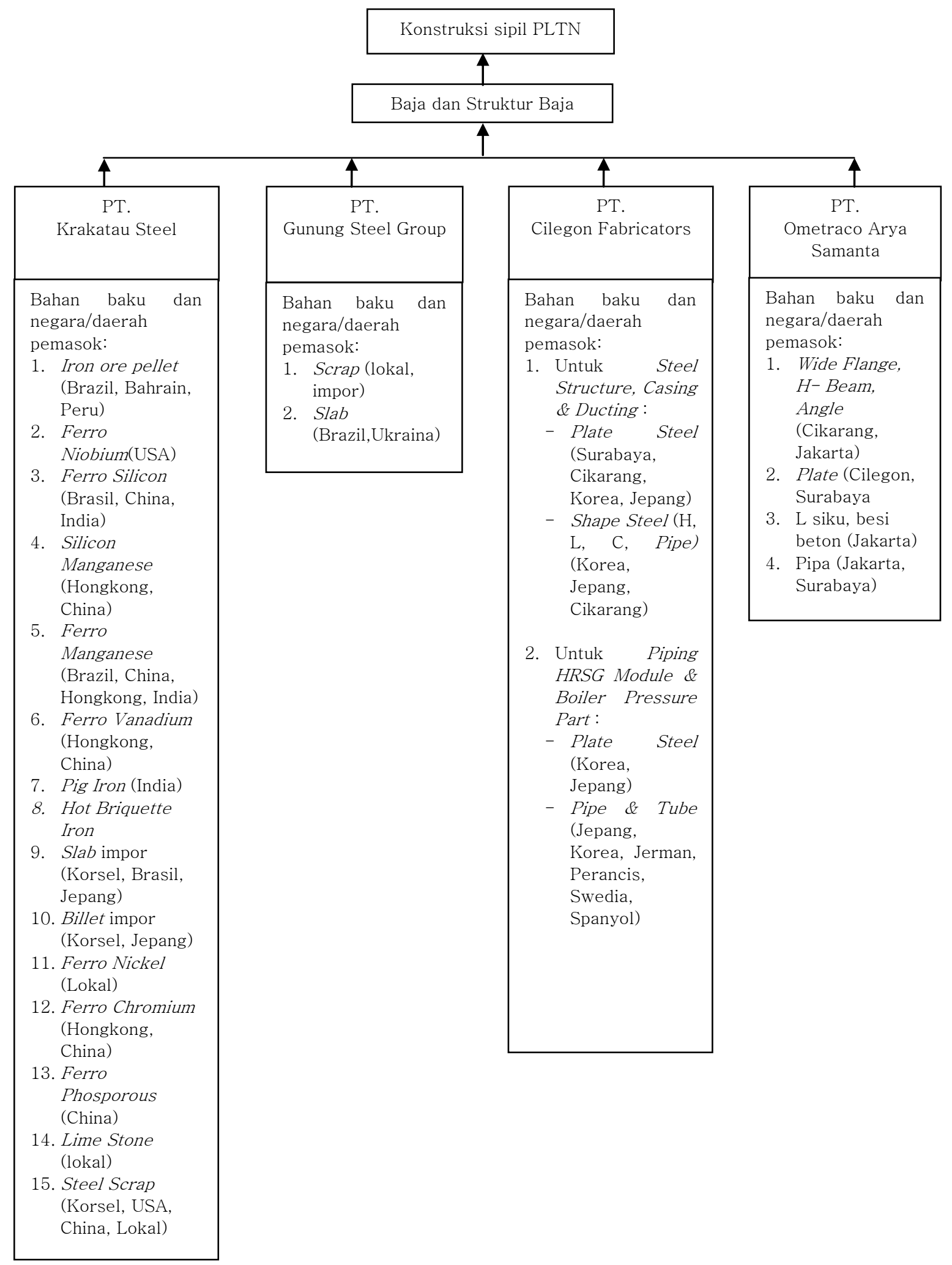

Gambar 3. Rantai Pasok Industri Baja Berdasarkan Jenis Bahan Baku dan Negara/Daerah Pemasok [26-29] 


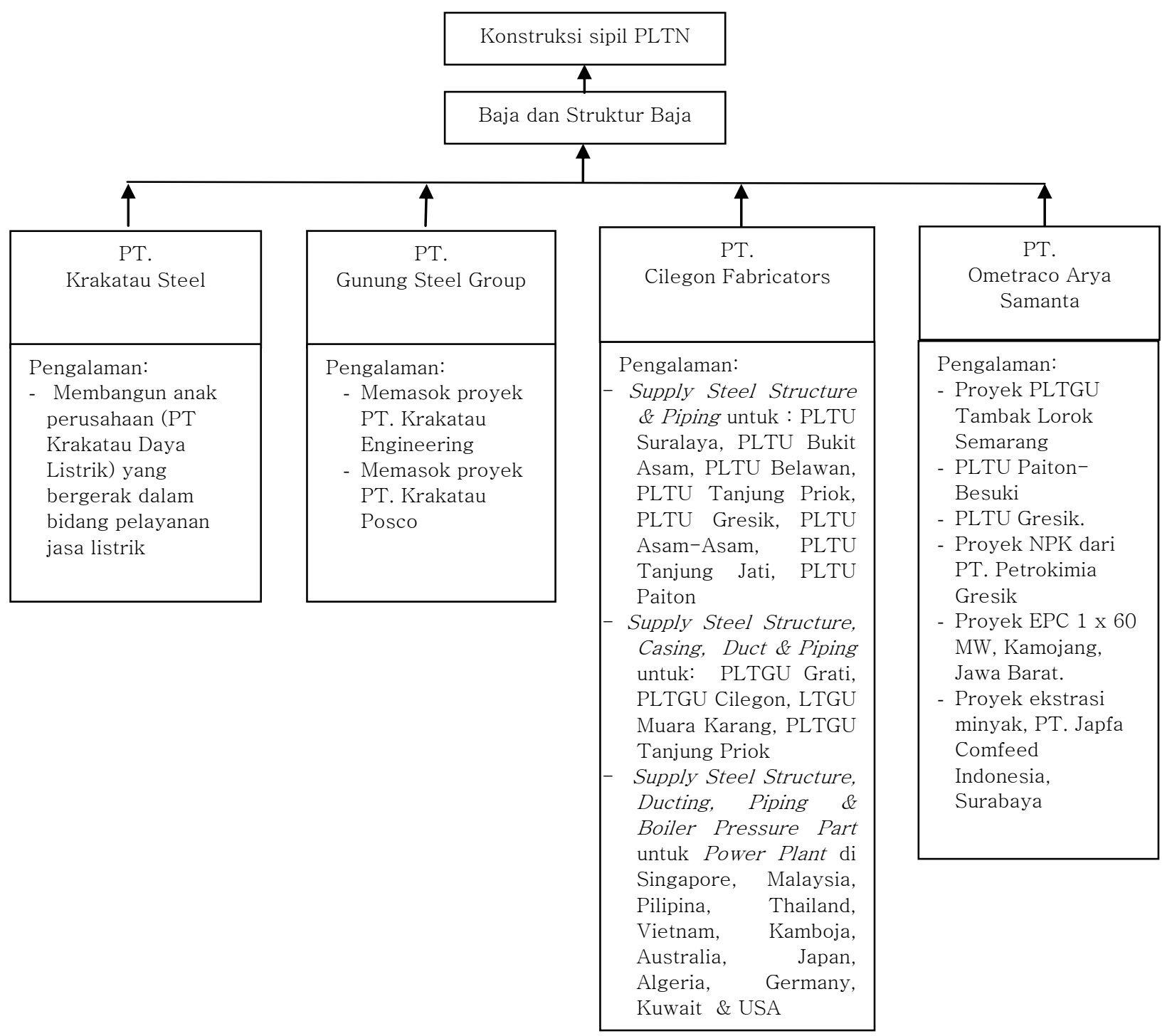

Gambar 4. Rantai Pasok Industri Baja Berdasarkan Pengalaman Industri [26-29]

Jenis produk dari PT. Ometraco Arya Samanta yakni pelayanan/jasa struktur baja dengan kapasitas 12.000 ton per tahun, pekerjaan pabrikasi pelat baja dengan kapasitas 2500 ton per tahun, dan bangunan sipil. Bahan baku Wide Flange, $H-$ Beam, dan Angle diperoleh dari industri lokal yakni Cikarang dan Jakarta, Plate diperoleh dari Cilegon dan Surabaya. PT. Ometraco Arya Samanta memiliki pengalaman dalam memasok pembangkit listrik konvensional yakni PLTGU Tambak Lorok, PLTGU Paiton dan lain lain. Hasil kuesioner dan survei industri, menunjukkan industri baja nasional telah mempunyai pengalaman cukup banyak dalam memasok ataupun ikut membangun Pembangkit Listrik Konvensional seperti
Pembangkit Listrik Tenaga Uap (PLTU), Pembangkit Listrik Tenaga Gas dan Uap (PLTGU) dan pembangkit listrik lainnya.

Potensi kemampuan industri baja di Indonesia agar dapat berpartisipasi dalam pembangunan PLTN di Indonesia, sangat penting untuk dikaji terlebih dahulu terkait spesifikasi, kode dan standar yang telah dipergunakan oleh pihak industri nasional di Indonesia sehingga peluang dan peranan industri baja dapat diidentifikasi sampai sejauh mana kesiapannya untuk mendukung pembangunan PLTN pertama di Indonesia. Penggunaan standar mutu internasional maupun standar nasional Indonesia bagi pihak industri akan dapat mengidentifikasi peluang industri tersebut untuk berpartisipasi dalam 
pembangunan PLTN. Secara umum industri baja di Indonesia mampu memasok baja dalam pembangunan PLTN khususnya pada bagian non nuklir. Sedangkan bahan baja untuk komponen-komponen utama dengan grade nuklir, seperti bahan baja untuk bejana reaktor dan bejana tekan, industri baja Indonesia belum mampu memasoknya.

Ketersediaan baja rebar, pelat baja, $H$ - beam dan lain-lain dapat dipenuhi oleh industri dalam negeri. Namun kecocokan spesifikasi, kode dan standar baja untuk konstruksi PLTN, masih perlu diidentifikasi lebih lanjut. Kemampuan pasokan industri baja Indonesia khususnya bahan baja untuk bagian non nuklir memiliki cukup kemampuan untuk berpartisipasi dalam pembangunan PLTN. Namun bahan baja untuk pembuatan komponen nuklir seperti bejana reaktor dan bejana tekan belum mampu memasoknya sehingga harus meningkatkan kemampuan baik dalam pengolahan bahan baku dan kemampuan fabrikasi agar dapat memenuhi memenuhi persyaratan grade nuklir atau spesifikasi, kode dan standar yang dipersyaratkan dalam PLTN. Hal ini akan dikaji pada studi tersendiri. Hasil survei menunjukkan bahwa rendahnya potensi bahan baku dalam negeri berdampak kepada rendahnya tingkat produksi. Rendahnya tingkat produksi menyebabkan rendahnya kinerja produktivitas dan daya saing industri baja nasional Indonesia di skala internasional. Biji besi yang ada di Indonesia sebagai bahan baku baja belum ekonomis untuk diolah, karena perlu teknologi yang padat modal untuk mengolahnya. Akibatnya, untuk dapat memenuhi kapasitas produksi, maka bahan baku tersebut lebih banyak diimpor[30]. Hal ini merupakan salah satu kendala dalam pemenuhan bahan baku bagi industri baja. Kendala lainnya adalah pengiriman bahan baku. Jika proses pengiriman material tertunda, maka hal tersebut akan mempengaruhi seluruh proses bisnis dan cash flow proyek sehingga strategi pemilihan material dan pemasok khususnya dari luar negeri harus ditentukan dan diperhitungkan secara teliti agar penyediaan material selalu berkelanjutan untuk mengantisipasi risiko tertundanya proyek.

\section{KESIMPULAN}

Industri baja Indonesia mempunyai kemampuan dalam memasok baja untuk pembangunan PLTN pada bagian non nuklir. Untuk memenuhi kebutuhan konstruksi PLTN di bagian nuklir, maka industri baja harus ditingkatkan kemampuannya untuk pengolahan bahan baku serta kemampuan fabrikasi agar dapat memenuhi persyaratan spesifikasi, kode dan standar PLTN sesuai dengan grade nuklir.

\section{DAFTAR ACUAN}

[1]. Michael D. Sherwin, Hugh Medal, Steven A. Lapp, "Proactive costeffective identification and mitigation of supply delay Risks in a low volume high value supply chain using faulttree analysis", International Journal Production Economics, Vol 175, pp 153-163, 2016.

[2]. Chopra, S., Sodhi, M.S., "Managing risk to avoid supply-chain breakdown", MIT Sloan Manag Review, Vol 46 (1), pp 53-61, 2004

[3]. Dharu Dewi, dkk, "Pemetaan Rantai Pasokan Industri Pembangunan PLTN di Indonesia”, Laporan Akhir Pelaksanaan Program Insentif Peningkatan Kemampuan Peneliti Dan Perekayasa, Kemenristek, 2012.

[4]. J. Pane, et al, "Planning for Local Industrial Involvement for New NPP Development in Indonesia”, Technical Meeting on Industrial Involvement and Localization for New Nuclear Power Plant Construction. International Atomic Energy Agency (IAEA), Crowne Plaza Hotel, Qingdao, China, 26 - 29 August 2014.

[5]. Dharu Dewi, dkk, "Rantai Pasok Industri Konstruksi Sipil untuk Mendukung Pembangunan PLTN di Indonesia”, Jurnal Pengembangan Energi Nuklir, Vol 15, pp 1-10, No 2, Desember 2013.

[6]. Dharu Dewi, dkk, "Supply Chain of Cement Industries to Support the Nuclear Power Plant Construction in Indonesia”, Prosiding Seminar Nasional 
Teknologi Energi Nuklir, Denpasar, 5 - 16 Oktober 2015,

[7]. M. R. Soltany, et al, "Productivity Improvement in a Steel Industry using Supply Chain Management Technique”, International Journal Min \& Geo-Eng (IJMGE), Vol. 47, No. 1, pp. 51-60. 2013 ,

[8]. S.C.L, Koh, et al, "Decarbonising Product Supply Chains: Design and Development of An Integrated Evidence-Based Decision Support System - The Supply Chain Environmental Analysis Tool (SCEnAT)“. International Journal of Production Research, Vol 51 No. 7, pp 2092-2109, 2012.

[9]. M. H. A. Nasir, et al, "Comparing Linear and Circular Supply Chains: A case study from the Construction Industry", International Journal of Production Economics, pp 443-457, 2017.

[10]. A. Acquaye, et al, "Benchmarking Carbon Emissions Performance in Supply Chains", Supply Chain Manag International Journal. Vol 19, No 3, 306-321, 2014.

[11]. E. Gokhan, et al, "Supply Chain-Linked Sustainability Assessment of The US Manufacturing: An Ecosystem Perspective", Journal of Sustainable Production and Consumption, Vol 5, pp 65-81, 2016.

[12]. H.M. Government, (2012,December), "The Nuclear Supply Chain Action Plan”,Available:https://www.gov.uk/go vernment/uploads/system/uploads/atta chment_data/file/65658/7176-nuclearsupply-chain-action-plan.pdf.

[13]. Mycle Schneider, et al, (2015 July 28), "The World Nuclear Industry Status Report 2015 (HTML), Pris, ,Available: http://www.worldnuclearreport.org/Th e-World-Nuclear-Industry-StatusReport-2015-HTML.html.

[14]. EDF Energy Nuclear Generation Ltd, 2016, "EDF Energy Nuclear Generation Supplier Quality Requirements Manual”,Available: https://www.edfenergy.com/sites/defau lt/files/supplier_quality_requirements_ manual_v5.pdf
[15]. K. R. W. Azfar, et al, "Performance Measurement: A Conceptual Framework for Supply Chain Practices", Procedia - Social and Behavioral Sciences, Vol 150, pp 803 812, 2014.

[16]. J. S. Kim, et al, "Strain-Based Plastic Instability Acceptance Criteria For Ferritic Steel Safety Class 1 Nuclear Components Under Level D Service Loads", Journal Nuclear Engineering and Technology, Vol 47, pp 340 - 350, 2015.

[17]. USNRC, (2011), "Recommendations for Enhancing Reactor Safety in the 21st Century: the Near Term Task Force Review of Insights from the Fukushima Dai-Ichi Accident",

Available:https/;//www.hsdl.org/?view $\&$ did $=696033$

[18] USNRC, 2010, "Implications of Updated Probabilistic Seismic Hazard Estimates in Central and Eastern United States on Existing Plants", Generic Issue 199, 2010.

[19]. A. H. Varma, et al, "Steel-Plate Composite (SC) Walls for Safety Related Nuclear Facilities: Design for in-Plane Forces and Out-of-Plane Moments", Journal of Nuclear Engineering and Design, Vol 269, pp 240-249,2014.

[20]. Kadir C. et al, "Steel-Plate Composite (SC) Walls: Out-of-plane flexural behavior, database, and design", Journal of Constructional Steel Research, Vol 108, pp 46-59, 2015.

[21]. D.T. Blagoeva, "Stability of Ferritic Steel to Higher Doses: Survey of Reactor Pressure Vessel Steel Data and Comparison with Candidate Materials for Future Nuclear Systems”, International Journal of Pressure Vessels and Piping, Vol 122, pp 1 - 5, 2015.

[22]. International Atomic Energy Agency, "Developing Industrial Infrastructure to Support a Programme of Nuclear Power", Technical Report Series no. 281, Vienna 1988.

[23]. Department of Energy, (2010) “DOE NP Nuclear Power Plant Construction Infrastructure 
Assessment", Washington DC, Available:www.nuclear.gov/np2010/rep orts/mpr2776Rev0102105.pdf

[24]. D. Dewi, S.M. Lumbanraja, "Studi Penyiapan SDM, Manufaktur, Fabrikasi Dan Peralatan Konstruksi PLTN Gen III+ Di Amerika Serikat", Seminar Nasional IV, SDM Teknologi Nuklir, 25 - 26 Agustus 2008, Yogyakarta. 2008.

[25]. J. J. Yoon, 2007, "Project Management (Structure and Architecture)", Korea Hydro Nuclear Power (KHNP) Co. Ltd, November 2007.

[26]. PPEN BATAN, "Kuesioner PT Krakatau Steel,”, 2012.

[27]. PPEN BATAN, "Kuesioner PT. Gunung Steel Group”, 2012
[28]. PPEN BATAN, "Kuesioner PT. Cilegon Fabricators, 2012,

[29] PPEN BATAN, "Kuesioner PT. Ometraco Arya Samanta, 2012.

[30]. P. E. Prasetyo, , "Struktur Dan Kinerja Industri Besi Dan Baja Indonesia Tidak Sekuat Dan Sekokoh Namanya", Jurnal Ekonomi dan Kebijakan (JEJAK), Vol 3, No 1, 2010, 